\title{
Protée
}

\section{Constanza Camelo Suarez}

\section{James Partaik}

Volume 38, numéro 1, printemps 2010

Le Groupe $\mu$ entre rhétorique et sémiotique

URI : https://id.erudit.org/iderudit/039706ar

DOI : https://doi.org/10.7202/039706ar

Aller au sommaire du numéro

Éditeur(s)

Département des arts et lettres - Université du Québec à Chicoutimi

\section{ISSN}

0300-3523 (imprimé)

1708-2307 (numérique)

Découvrir la revue

Citer ce document

Partaik, J. (2010). Constanza Camelo Suarez. Protée, 38(1), 94-103.

https://doi.org/10.7202/039706ar d'utilisation que vous pouvez consulter en ligne.

https://apropos.erudit.org/fr/usagers/politique-dutilisation/ 


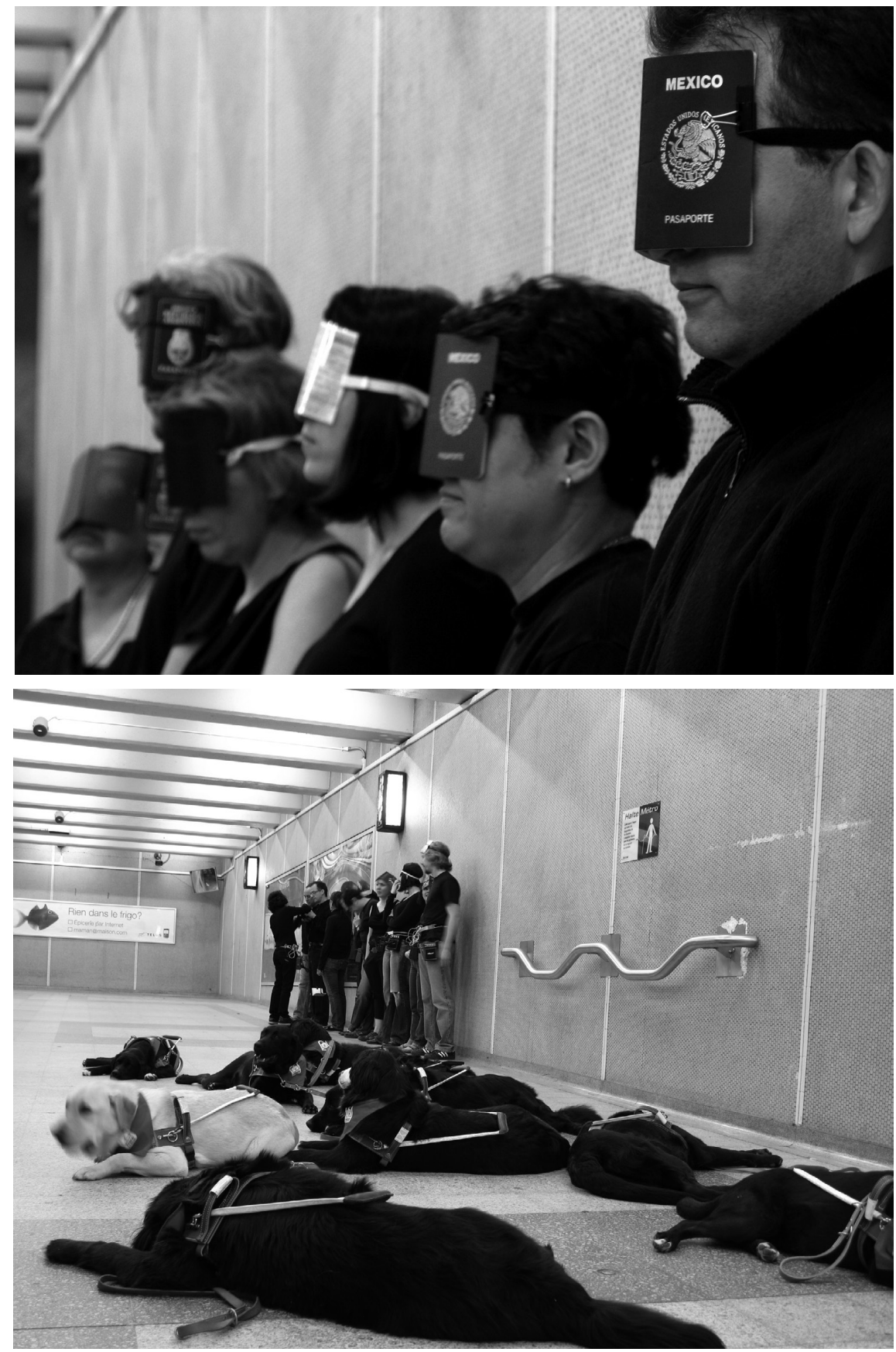




\section{CONSTANZA CAMElO SUAREZ}

onstanza Camelo Suarez réalise des manœuvres, performances-vidéo et installActions depuis 1995. Sa pratique explore des interactions entre divers dispositifs interdisciplinaires opérés lors de cohabitations éphémères d'espaces publics et privés.

Selon l'artiste, le corps se déplace dans des non-lieux réactivant leur sens contextuel de manière in situ. L'union des émergences du territoire, de l'objet et de l'action vise à fabriquer des interventions où le poétique et le politique interagissent.

La participation ou la collaboration d'autres personnes et communautés transforment cette pratique en échanges intersubjectifs de résistance ontologique: résistance à la mort à travers l'apparition d'une présence ponctuelle et moment d'épiphanie.

Lors de la mise en acte de concepts à soulever, l'art action devient tactique de détournement de I'homogénéisation culturelle. Matériaux vivants, le corps et l'espace investis donnent lieu à une prise de position identitaire par l'esthétique et l'éthique, le secret et la solidarité.

L'artiste affirme:

Todorov définit le rôle de l'intellectuel comme celui d'un savant ou d'un artiste qui ne se borne pas seulement à faire son œuvre à l'intérieur de son domaine de travail, mais qui, de plus, se sent concerné par les valeurs de sa société et participe au débat public de ces valeurs. Pour Todorov, I'artiste-intellectuel serait l'individu qui, intéressé par la problématique du beau, accompagnerait cette dernière d'une deuxième problématique, celle du bien. L'artiste intellectuel serait un individu qui se situerait entre deux champs de recherche: celui de l'esthétique, espace de l'imagination, et celui de l'éthique, espace de la conscience.

La pratique de Constanza Camelo Suarez correspond à celle d'une artiste et d'une intellectuelle. En cherchant à construire des points de rencontre entre la précarité de la vie humaine et sa possibilité d'être et d'habiter dans le monde, elle vise à établir des ponts entre le processus et la permanence, à réfléchir sur les modes de construction de la mémoire.

James Partaik 


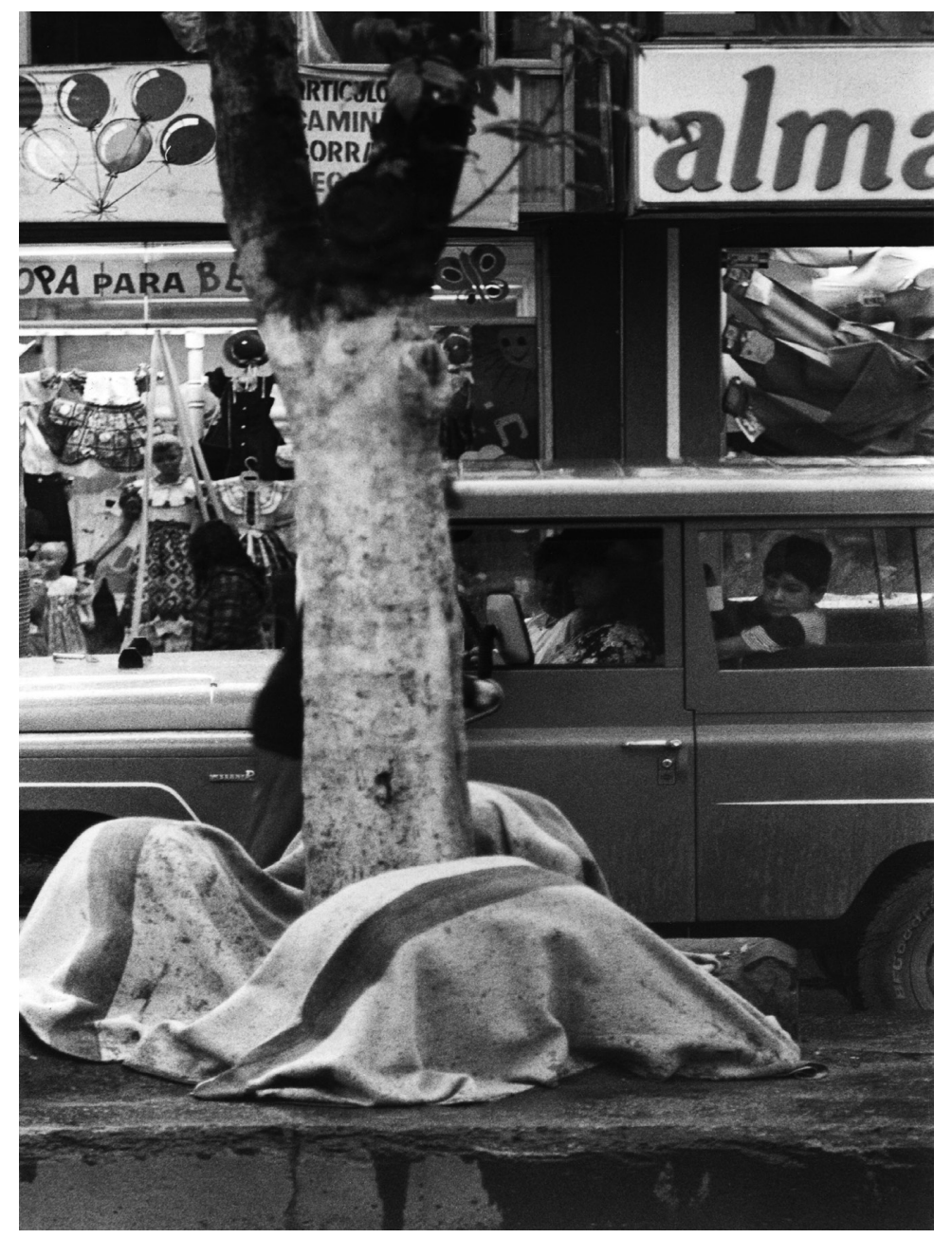




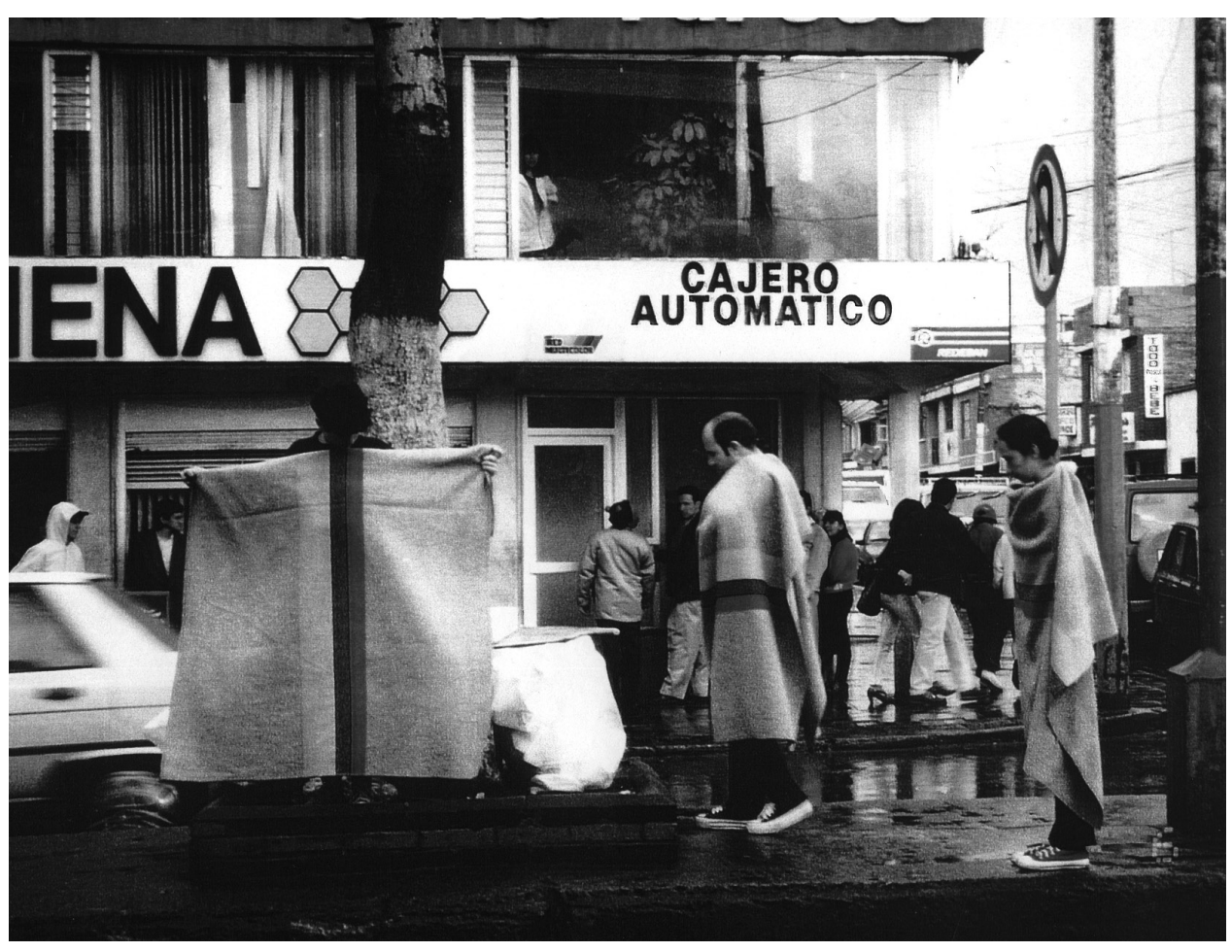




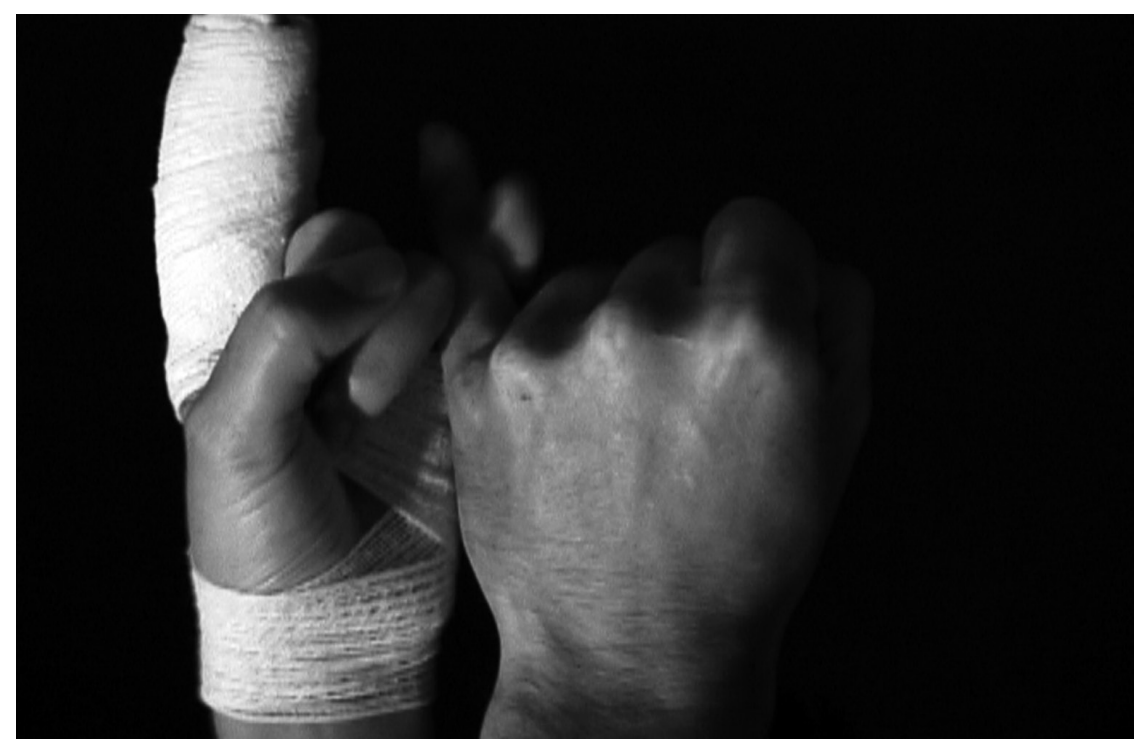




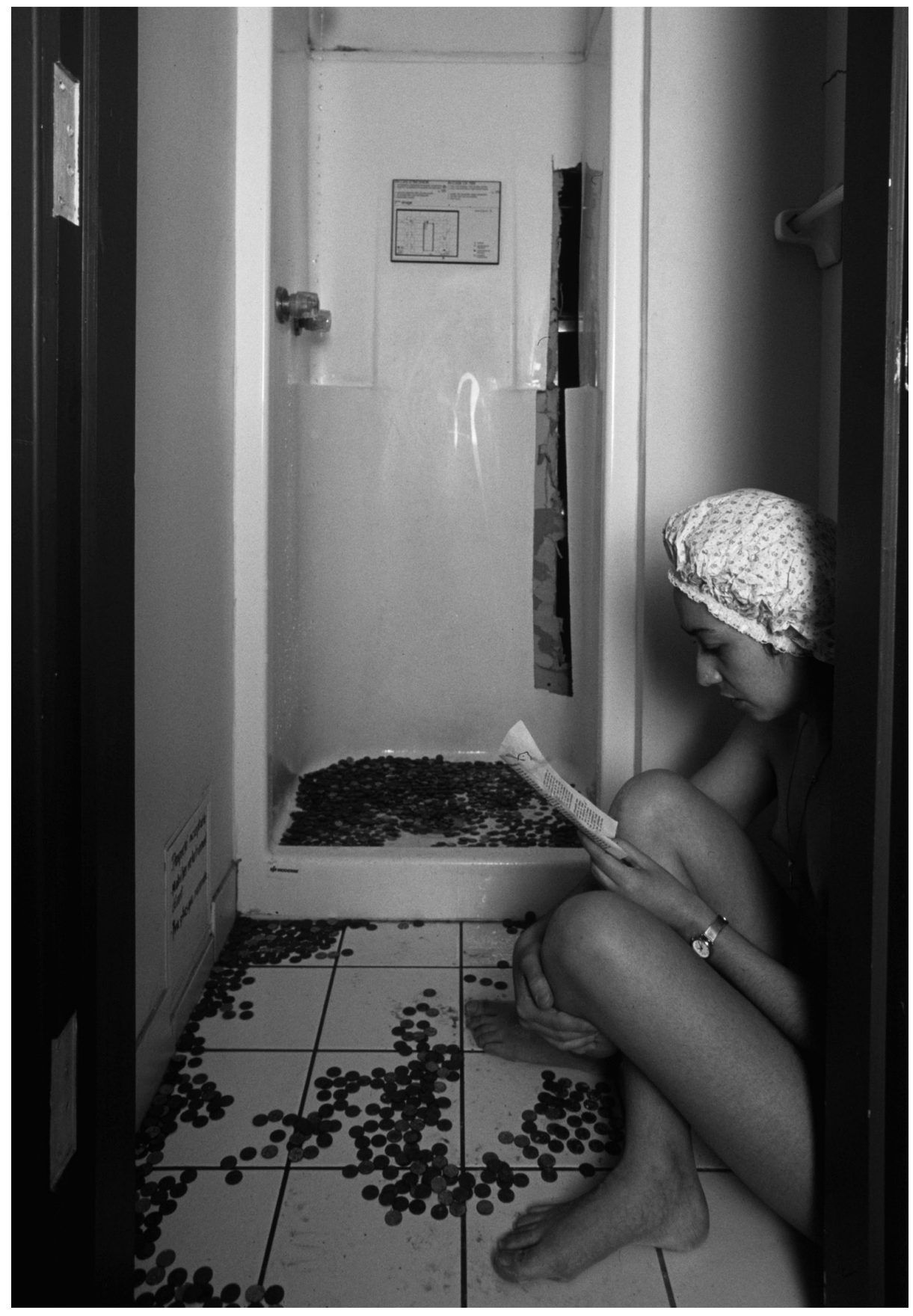



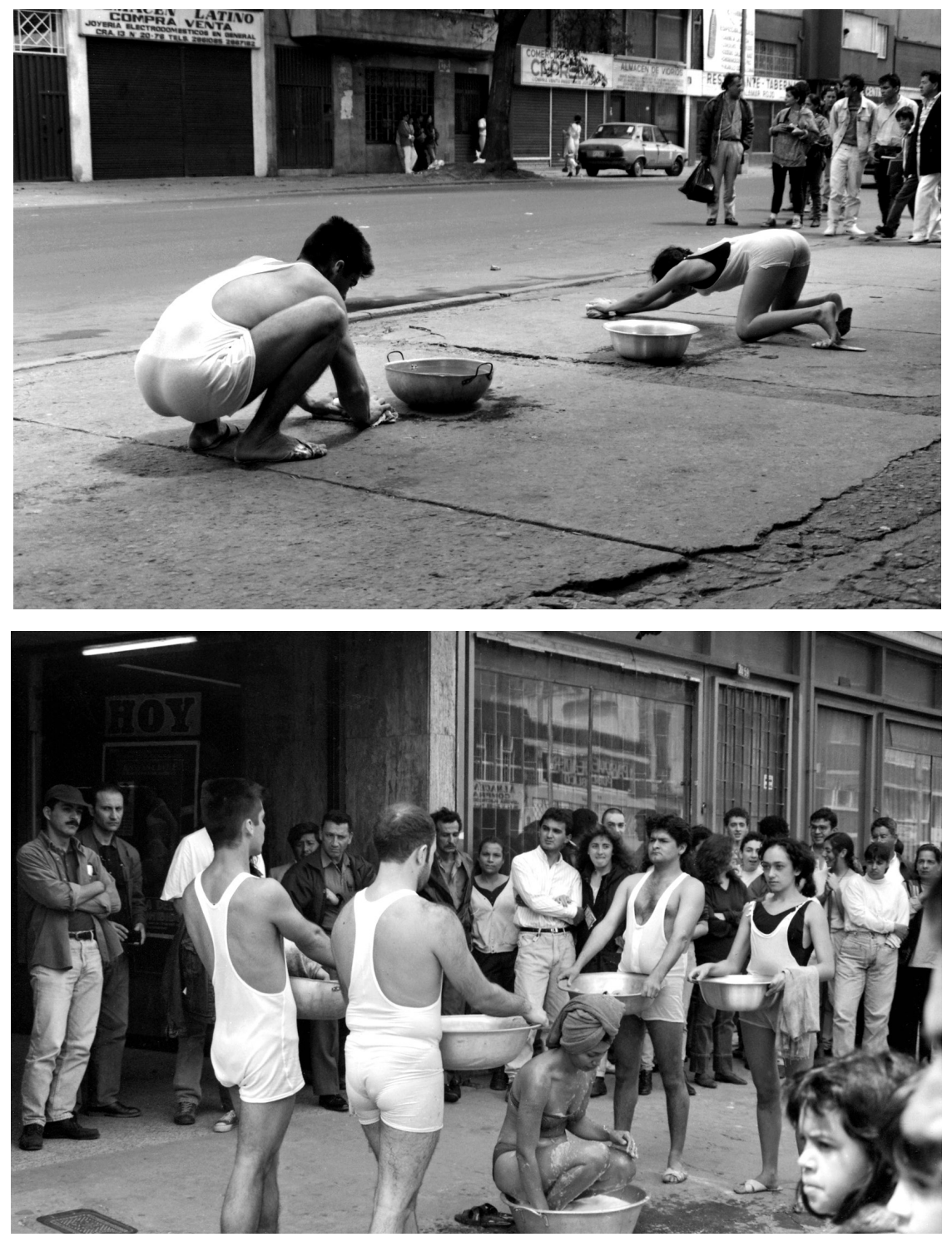


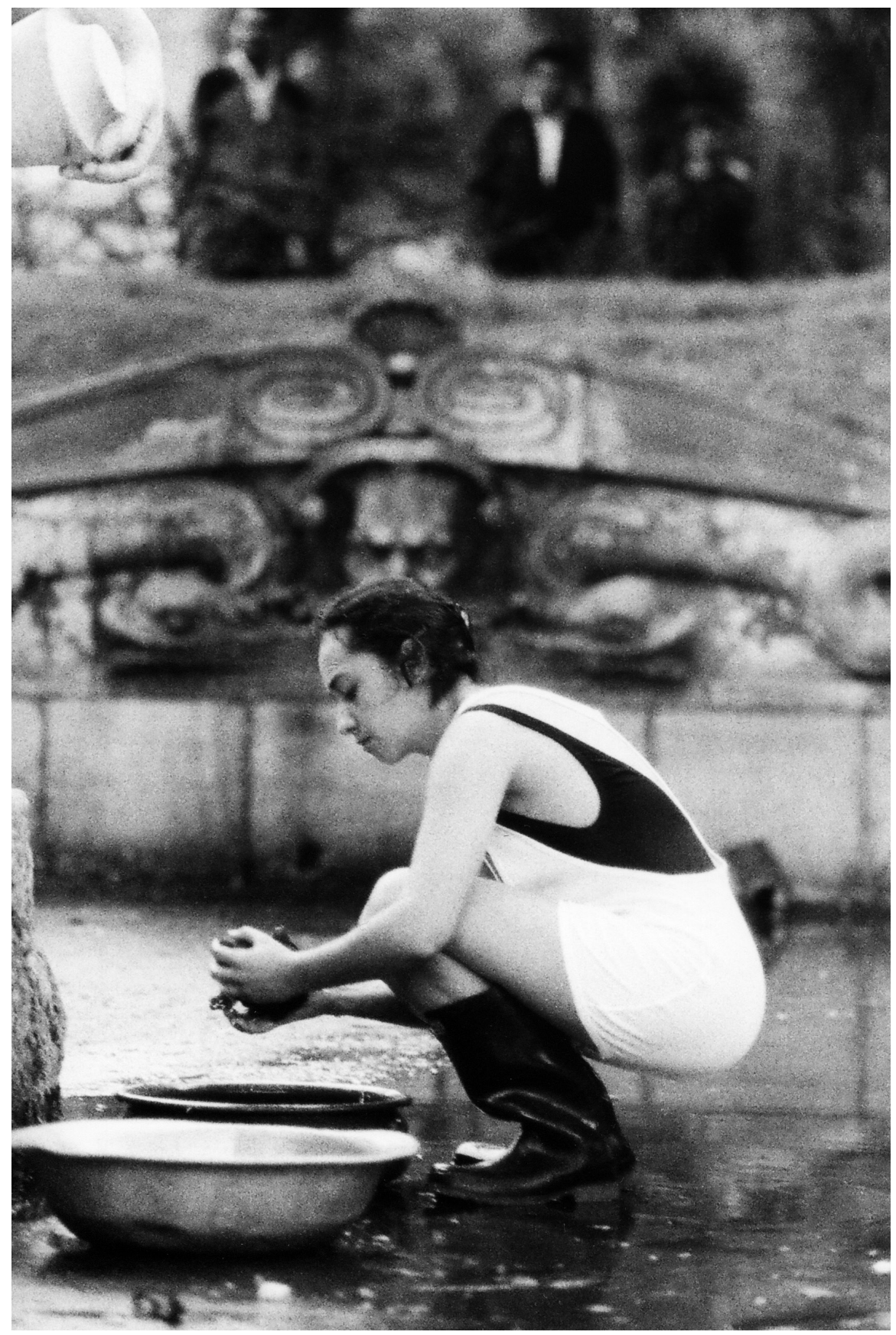




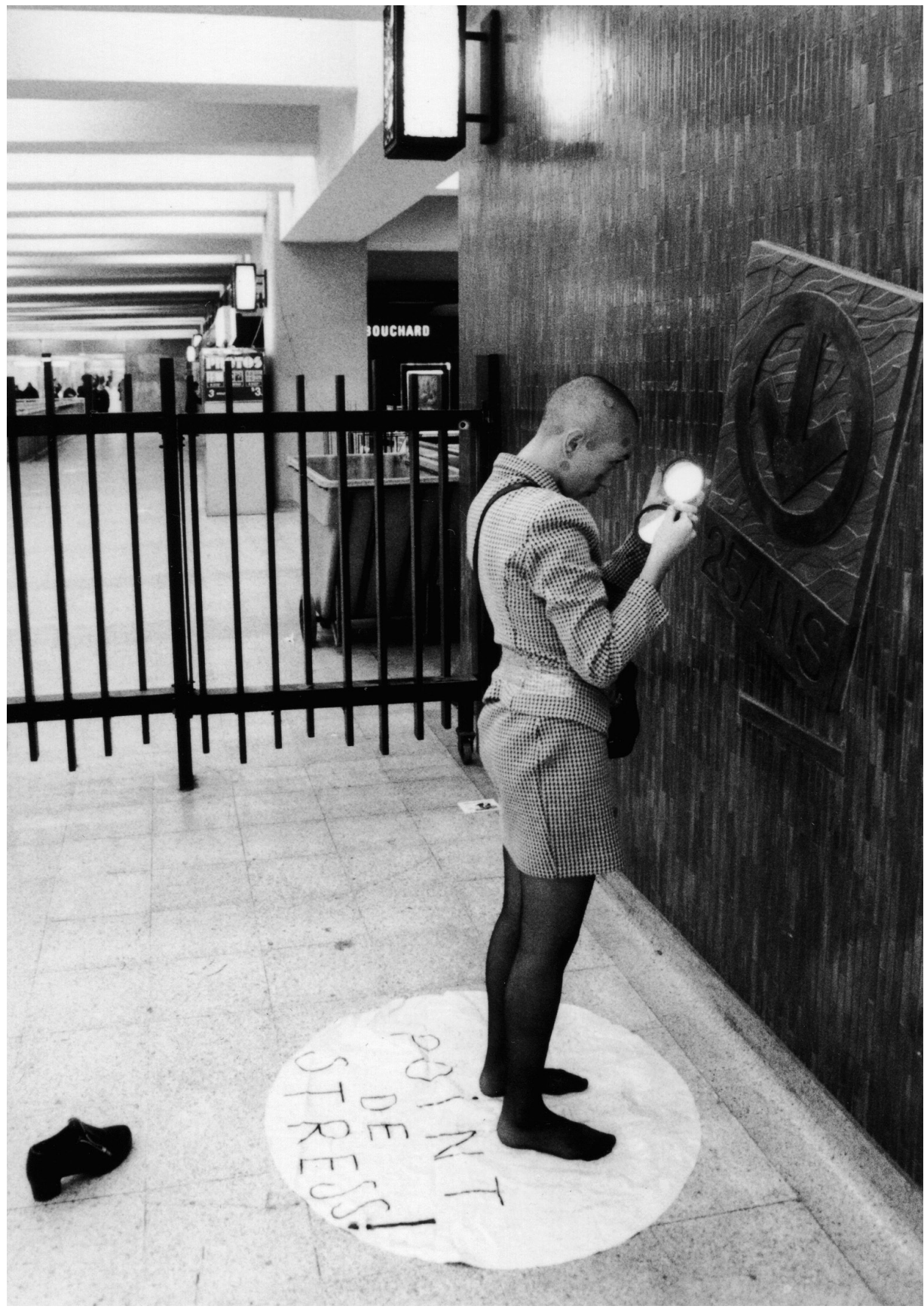




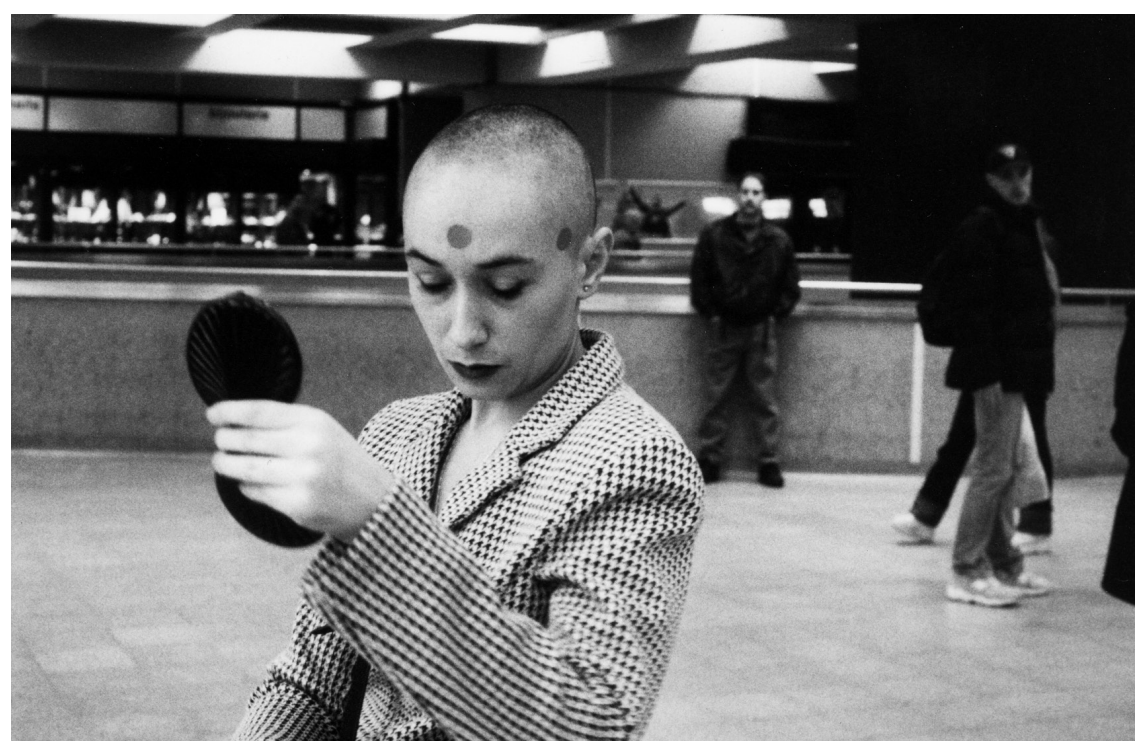

page 94

Dilater ou contracter I'univers I. Intervention performative, station de métro Berri-UQAM, Montréal 2008;

pages 96 et 97

Abri - Cobijo. Intervention performative, séparation de rue, quartier Venecia, Bogota, 1995 ;

page 98

L'amour aveugle/Blind Love. Manœuvre vidéo, cinéma L'Amour, Montréal (Festival FA3), 2001

(en collaboration avec James Partaik);

page 99

Les tas/L'É(é)tat de nos pays, The State of our Countries. InstallAction, pension en rénovation, rue Saint-Denis, Montréal (48 hours, 48 rooms), 1999 (en collaboration avec James Partaik);

pages 100 et 101

Journées de nettoyage/Cleaning Day I,II. Intervention performative, Bogota, 1994 ;

pages 102 et 103

Point de stress !/ Sress point! Intervention performative, station de métro Berri-UQAM, Montréal, 1998. 